\title{
Organochlorine pesticides in particulate matter of Beijing, China
}

\author{
Xiaofei Wang ${ }^{\mathrm{a}}$, Xinghong $\mathrm{Li}^{\mathrm{a}}$, Hangxin Cheng ${ }^{\mathrm{b}}$, Xiaobai Xu ${ }^{\mathrm{a}, *}$, \\ Guangmin Zhuang ${ }^{\mathrm{b}}$, Chuandong Zhao ${ }^{\mathrm{b}}$ \\ a State Key Laboratory of Environmental Chemistry and Ecotoxicology, Research Center for Eco-Environmental Sciences, \\ Chinese Academy of Sciences, P.O. Box 2871, Beijing 100085, China \\ ${ }^{\mathrm{b}}$ Institute of Geophysical \& Geochemical Exploration, Chinese Academy of Geological Science, Langfang 065000, China
}

Received 7 October 2007; received in revised form 15 November 2007; accepted 20 November 2007

Available online 5 December 2007

\begin{abstract}
Eighteen organochlorine pesticides (OCPs) in air particulate matter (PM) samples collected from 20 sites in Beijing, China in 2005 and 2006 were analyzed to determine the composition, spatial distribution and sources. Total OCPs of $\mathrm{PM}_{2.5}$ and $\mathrm{PM}_{10}$ ranged from $32.59 \mathrm{pg} \mathrm{m}^{-3}$ to $9232.31 \mathrm{pg} \mathrm{m}^{-3}$ and $80.96 \mathrm{pg} \mathrm{m}^{-3}$ to $9434.97 \mathrm{pg} \mathrm{m}^{-3}$, respectively, categorized as heavier pollution compared to other cities of China. Among six kinds of functional zones involved, commercial areas and industrial centers were heavily polluted. Distinct concentrations variations were detected in PM with different particle diameters. Pollution distribution was spatially heterogeneous inside the city. The most heavily polluted sites located in the southeast part of the city, where laid many chemical factories. Compositional analysis and principal component analysis (PCA) suggested that past usage of OCPs was the main source, though there were new inputs in some sites.
\end{abstract}

(C) 2007 Elsevier B.V. All rights reserved.

Keywords: Particulate matter (PM); Organochlorine pesticide (OCPs); Principal component analysis (PCA)

\section{Introduction}

Organochlorine pesticides (OCPs) were worldwide used in agriculture from the 1950s to the 1970 . Over the past 30 years, OCPs received extensive concerns due to their nature of persistence [1], biomagnifying [2], and endocrine disrupting effects [1-3]. Some OCPs were banned and restricted on usage in developed countries in 1970s and 1980s, however, many developing countries are still using them for agricultural and public health purpose because of low cost and the good effect in controlling insects $[4,5]$. As a result, OCPs are still in use or present as residues of previous usage and remain major global pollution [6]. Early surveys reported OCPs in a wide range of environmental compartments almost everywhere in the world including the remote sites such as Arctic, Himalayas, etc. [7-9]. Atmospheric particles plays an important role in OCPs transportation [6], and they are believed to have relevance with many lung dieses [10]. Thus, measurements of OCPs in particulate matters of high population load are necessary.

\footnotetext{
* Corresponding author. Tel.: +86 1062919177 ; fax: +86 1062923563.

E-mail address: xuxb5@sohu.com (X.Xu).
}

Parallel with urban development, Beijing $\left(39^{\circ} 48^{\prime} \mathrm{N}\right.$ and $116^{\circ} 28^{\prime} \mathrm{E}$ ), the capital of China, has received a lot of pollution load including OCPs, which were used in Beijing for 30 years prior to being prohibited in 1983. It is reported that hexachlorocyclohexanes (HCHs) and dichlorodiphenyltrichloroethanes (DDTs) accounted for $83.3 \%$ of total pesticides sold in Beijing before 1979. Till now, OCPs continue to be detected in atmosphere, water, soil, and biota of Beijing [11-14]. An earlier survey [11] has reported HCHs and DDTs residues were $240 \mathrm{pg} \mathrm{m}^{-3}$ and $962 \mathrm{pg} \mathrm{m}^{-3}$ in total suspend particles (TSP), $130 \mathrm{pg} \mathrm{m}^{-3}$ and $528 \mathrm{pg} \mathrm{m}^{-3}$ in $\mathrm{PM}_{2.5}$ of Beijing. Xu et al. [13] reported HCHs were $17.9 \mathrm{pg} \mathrm{m}^{-3}$ and $17.3 \mathrm{pg} \mathrm{m}^{-3}$ in $\mathrm{PM}_{2.5}$ and $\mathrm{PM}_{10}$, DDTs were $23.5 \mathrm{pg} \mathrm{m}^{-3}$ and $16.7 \mathrm{pg} \mathrm{m}^{-3}$ in $\mathrm{PM}_{2.5}$ and $\mathrm{PM}_{10}$. However, these reports focused on limited sites in this city and could not reflect the general situation of air pollution in Beijing. To get an overall understanding of air OCPs level and develop an effective air pollution control, it is necessary to carry out a detailed and systematic investigation in a municipal scale.

We have performed a 1-month air particulate matter $\left(\mathrm{PM}_{2.5}\right.$ and $\mathrm{PM}_{10}$ ) sampling in winter at 20 sites that covered city zone of Beijing. It was reported that OCPs level was least in winter [15], so that the aerosol samples in winter can be regarded as representative for the lightest pollution status in the city and are 
of importance in air quality controlling. We focused on sources and spatial distribution of OCPs. The abundance and characteristic of OCPs also discussed. The objectives of this study are: (1) to give the OCPs levels of PM in Beijing; (2) to identify the most polluted area and the health risk of OCPs in these city area; and (3) to give an advice on OCPs controlling.

\section{Materials and methods}

\subsection{Materials and reagents}

A mixed stock standard solution of OCPs containing $\alpha-\mathrm{HCH}$, $\beta-\mathrm{HCH}, \gamma-\mathrm{HCH}, \delta-\mathrm{HCH})$, heptachlor, heptachlor epoxide, cis-chlordane (CC), trans-chlordane (TC), $\alpha$-endosulfan, $\beta$-endosulfan, endosulfan sulfate, diedrin, endrin, aldrin, $p, p^{\prime}$-DDE, $p, p^{\prime}$-DDD, $p, p^{\prime}$-DDT each at concentration of $1000 \mu \mathrm{g} \mathrm{mL}^{-1}$ was obtained from Chem service. The $o, p^{\prime}$ DDT standard solution of $100 \mathrm{mg} \mathrm{L}^{-1}$ was purchased from National Research Center for Certified Reference Materials of China. Hexachlorobenzene (HCB) and 2,4,5,6-tetrachloromxylene (TCMX, the surrogate) was bought from Supelco (Bellfonte, USA). The working standards were prepared by diluting the above-mentioned standard solution with isooctane. Florisil (a selective adsorbent for chromatography, Dikma Co. USA) was activated at $600^{\circ} \mathrm{C}$ for $6 \mathrm{~h}$ and then at $130{ }^{\circ} \mathrm{C}$ for $16 \mathrm{~h}$. Hexane and ethyl ether (Dikma, USA) used were of pesticide grade. Acetone (Beijing Chemical Factory, China) was of analytical grade and redistilled in all-glass system prior to use.

\subsection{Sampling and preparation}

The suspended particulate matters were collected onto glass fiber filters (GF/C) (\$90 mm, Whatman Company, UK) using medium volume samplers (Model TH-150, Wuhan Tianhong Instrument Factory) at a flow rate of $100 \mathrm{~L} \mathrm{~min}^{-1}$ in winter from 20 sites of Beijing, China (Fig. 1 and Table 1). The sampling times were chosen to be representative of the seasonal meteorological conditions (average temperature is about $-4.6{ }^{\circ} \mathrm{C}$ ). Four-hour samples were collected. Before the experiment, the

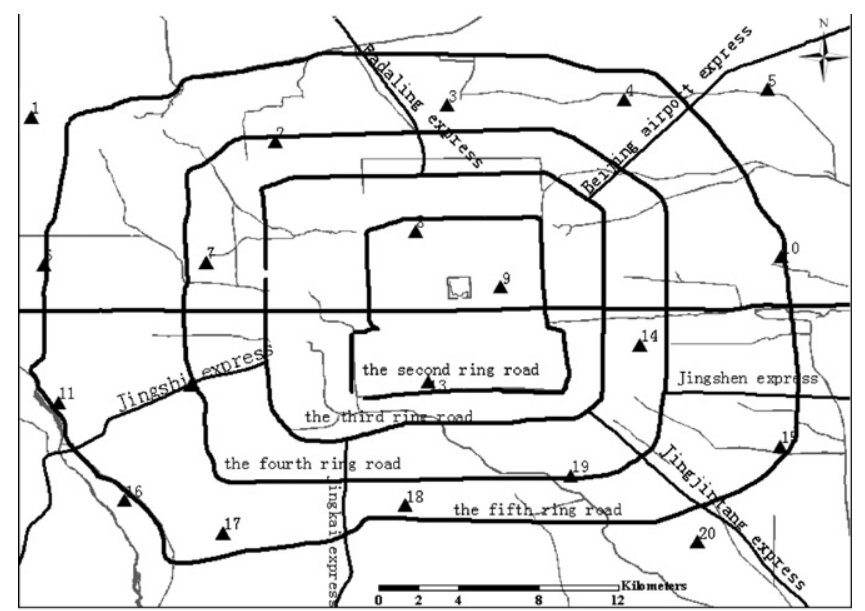

Fig. 1. Map of sampling sites in Beijing.
Table 1

Information for sampling sites

\begin{tabular}{rll}
\hline Sites & Sites type & Dates \\
\hline 1 & Residential area & 20 December 2005 \\
2 & Commercial area & 21 December 2005 \\
3 & Building site & 22 December 2005 \\
4 & Power plant & 25 December 2005 \\
5 & Village & 26 December 2005 \\
6 & Campus & 27 December 2005 \\
7 & Residential area & 28 December 2005 \\
8 & Hospital yard & 31 December 2005 \\
9 & Commercial area & 05 January 2006 \\
10 & Industrial center & 06 January 2006 \\
11 & Industrial center & 09 January 2006 \\
12 & Crossroad & 10 January 2006 \\
13 & Park & 11 January 2006 \\
14 & Residential area & 12 January 2006 \\
15 & Industrial center & 15 January 2006 \\
16 & Desertification area & 16 January 2006 \\
17 & Park & 17 January 2006 \\
18 & Farm & 18 January 2006 \\
19 & Plaza & 19 January 2006 \\
20 & Industrial center & 23 December 2005 \\
& &
\end{tabular}

filters were previously annealed for $4 \mathrm{~h}$ at $550{ }^{\circ} \mathrm{C}$ to remove organic material and equilibrated in desiccators, weighted and put into an envelope pretreated at $550{ }^{\circ} \mathrm{C}$. After sampling, the filters were removed from the inlet and folded in half and returned to the envelope and transported to the laboratory as soon as possible. The filters were stored in a desiccator to equilibrate for at least $24 \mathrm{~h}$ before being weighed. After being weighed, the samples were stored in a refrigerator at $-18{ }^{\circ} \mathrm{C}$ until analysis.

\subsection{Sample extraction and cleanup}

After $1 \mathrm{~mL}$ of TCMX (100 $\mathrm{ng} \mathrm{mL}^{-1}$ ) added, the filter was ultrasonically extracted in $30 \mathrm{~mL}$ acetone/hexane (1/1) thrice during $6 \mathrm{~min}$ and centrifuged for separation. Then the solvent was rotary evaporated at vacuum and then reduced to $1 \mathrm{~mL}$ at gentle stream of nitrogen. The concentrated extract was further cleaned up with a Florisil column $(30 \mathrm{~cm} \times 10 \mathrm{~mm}$ id $)$ packed with $5 \mathrm{~g}$ of florisil (in hexane). After the sample was transferred onto the column, it was then eluted with $40 \mathrm{~mL}$ hexane/ethyl ether $(7 / 1, v / v)$. The elute was concentrated in a rotary vacuum evaporator and the reduced to $0.1 \mathrm{~mL}$ by a gentle nitrogen stream for determination.

\subsection{OCPs determination}

The determination of OCPs was performed on a Agilent $6890 \mathrm{GC}-\mu \mathrm{ECD}$ equipped with a fused silica capillary DB-5 column $(30 \mathrm{~m} \times 0.25 \mathrm{~mm}$ i.d., $0.25 \mu \mathrm{m}$ film thickness $)$. Nitrogen was used as both carrier and makeup gas. Inlet and detector temperature were $225^{\circ} \mathrm{C}$ and $310^{\circ} \mathrm{C}$ each. The oven temperature program was as follows: initial temperature $100^{\circ} \mathrm{C}$ held for $2 \mathrm{~min}$, increased to $160^{\circ} \mathrm{C}$ at $10^{\circ} \mathrm{C} \mathrm{min}^{-1}$, then to $230^{\circ} \mathrm{C}$ at $4{ }^{\circ} \mathrm{C} \mathrm{min}{ }^{-1}$ for $5 \mathrm{~min}$, and to $280{ }^{\circ} \mathrm{C}$ at $10^{\circ} \mathrm{C} \mathrm{min}^{-1}$, held for $10 \mathrm{~min}$. One microlitre of each sample was injected in the splitless mode. Identification of the compounds was based on the 
retention time with corresponding standards and confirmed on an Agilent 6890GC equipped with a 5973 mass selective detector (MSD). The quantification of the analytes was performed by comparison to external standard.

The recoveries of OCPs spiked in matrix were in the range of $75 \%-115 \%$, and R.S.D. $(n=5)$ was $4-12 \%$. The recoveries of surrogate (TCMX) spiked in blank, matrix, samples were between $84 \%$ and $109 \%$.

\subsection{Data analysis}

The spatial distribution of pollutants was determined by ArcGIS 9.0. Statistical analysis was performed with SPSS 13.0.

\section{Results and discussion}

\subsection{OCPs concentration}

The total OCPs (sum of 18 OCPs) concentrations of $\mathrm{PM}_{2.5}$ and $\mathrm{PM}_{10}$ were in the range of $32.59-9232.31 \mathrm{pg} \mathrm{m}^{-3}$ and 80.96-9434.97 $\mathrm{pg} \mathrm{m}^{-3}$, respectively. The highest concentration appeared in a plaza (site 19) in the southern part for both $\mathrm{PM}_{2.5}$ and $\mathrm{PM}_{10}$ while the lowest dose detected in a village (site 5) for $\mathrm{PM}_{2.5}$ and a residential area (site 14) for $\mathrm{PM}_{10}$. Average concentration of individual OCPs was listed in Table 2. It is interesting that concentrations of most OCPs were high in $\mathrm{PM}_{10}$ except for heptachlor, aldrin and heptachlor epoxide. Besides, $\mathrm{PM}_{10}$ had higher FD (detection of frequency) of OCPs than $\mathrm{PM}_{2.5}$. This could be related with the fact that most OCPs tend to be strongly absorbed by coarse air particles.

It was observed HCHs, DDTs, HEPTs (heptachlor + heptachlor epoxide), chlordanes (trans-chlordane + cis- chlordane) and aldrins (aldrin + dieldrin + endrin) had positive correlation relationship with $\Sigma$ OCPs in both $\mathrm{PM}_{2.5}$ and $\mathrm{PM}_{10}$ samples (Table S-1, supporting material). However, HCB and endosulfans ( $\alpha$-endosulfan $+\beta$-endosulfan $)$ had poor relationship with $\Sigma$ OCPs.

It was worth noticing that aldrin, dieldrin and endrin had never been used in large amounts in China, but were detected at high levels in most of PM samples in Beijing. The three compounds were also detected in surface water and sediments from Guanting Reservoir [5] and in most water samples from Qiantang River [16]. The high levels of these compounds in PM samples are possibly transported by air parcels from abroad. As these three compounds are still used in some developing countries around the tropical belt, there is possibility that they move through atmosphere circulation to higher latitude regions.

Although pesticide pollution of air has been well documented around the world, there were limited research data on these 18 OCPs, thus only $\Sigma$ HCHs and $\Sigma$ DDTs in PM were compared with that in other cities in China, such as TSP in Tianjin $\left(1.05 \pm 1.88 \mathrm{ng} \mathrm{m}^{-3}\right.$ for $\Sigma \mathrm{HCHs}$ and $0.839 \pm 0.713 \mathrm{ng} \mathrm{m}^{-3}$ for $\Sigma$ DDTs) [17], Guangzhou $\left(2 \mathrm{pg} \mathrm{m}^{-3}\right.$ for $\alpha-+\gamma-\mathrm{HCH}$, $91.5 \mathrm{pg} \mathrm{m}^{-3}$ for DDTs ( $p, p^{\prime}$-DDE, $p, p^{\prime}$-DDD, $o, p^{\prime}$-DDT)), Hongkong (n.d. for HCHs and $18.5 \mathrm{pg} \mathrm{m}^{-3}$ for DDTs $\left(p, p^{\prime}-\right.$ DDE, $p, p^{\prime}$-DDD, $o, p^{\prime}$-DDT)) [15]. The results showed that PM in Beijing was heavily polluted by OCPs.

One of the main focuses of this study is to check the current status of OCPs pollution in different city function zones of Beijing. Five major zones (industrial center, commercial area, residential area, village and park) were divided according to surrounding environment of the sampling sites. In general, commercial areas and industrial centers showed high level of OCPs. For $\mathrm{PM}_{2.5}$, the average concentration of OCPs was in the order of

Table 2

Compounds analyzed $\left(\mathrm{pg} \mathrm{m}^{-3}\right)$

\begin{tabular}{|c|c|c|c|c|c|}
\hline \multirow[t]{2}{*}{ Compounds } & \multirow[t]{2}{*}{ MW } & \multicolumn{2}{|l|}{$\mathrm{PM}_{2.5}\left(\mathrm{pg} \mathrm{m}^{-3}\right)$} & \multicolumn{2}{|l|}{$\mathrm{PM}_{10}\left(\mathrm{pg} \mathrm{m}^{-3}\right)$} \\
\hline & & Mean & $\mathrm{FD} \%$ & Mean & $\mathrm{FD} \%$ \\
\hline$\alpha-\mathrm{HCH}$ & 291 & $69.90 \pm 88.78$ & 95 & $78.65 \pm 64.26$ & 95 \\
\hline $\mathrm{HCB}$ & 284.79 & $53.74 \pm 28.06$ & 95 & $82.24 \pm 65.41$ & 95 \\
\hline$\beta-\mathrm{HCH}$ & 291 & $39.68 \pm 48.90$ & 70 & $50.26 \pm 62.56$ & 85 \\
\hline$\gamma-\mathrm{HCH}$ & 291 & $54.22 \pm 31.48$ & 100 & $74.37 \pm 58.25$ & 100 \\
\hline$\delta-\mathrm{HCH}$ & 291 & $53.43 \pm 30.23$ & 95 & $90.69 \pm 64.33$ & 100 \\
\hline Heptachlor & 373.5 & $99.93 \pm 190.20$ & 95 & $72.91 \pm 49.17$ & 100 \\
\hline Aldrin & 365 & $376.08 \pm 542.35$ & 95 & $333.48 \pm 435.06$ & 100 \\
\hline Heptachlor epoxide & 389.2 & $299.77 \pm 436.37$ & 95 & $255.07 \pm 336.21$ & 100 \\
\hline trans-Chlordane & 409.8 & $269.29 \pm 311.04$ & 90 & $321.86 \pm 324.25$ & 100 \\
\hline$\alpha$-Endosulfan & 406.9 & $53.17 \pm 34.88$ & 95 & $92.45 \pm 104.39$ & 100 \\
\hline cis-Chlordane & 409.8 & $51.89 \pm 58.35$ & 85 & $81.22 \pm 83.83$ & 90 \\
\hline$p, p^{\prime}-\mathrm{DDE}$ & 318 & $104.29 \pm 74.43$ & 90 & $194.69 \pm 204.72$ & 95 \\
\hline Dieldrin & 381 & $49.66 \pm 43.99$ & 90 & $60.50 \pm 53.95$ & 90 \\
\hline Endrin & 381 & $107.15 \pm 89.43$ & 85 & $136.83 \pm 180.46$ & 90 \\
\hline$\beta$-Endosulfan & 406.9 & $78.78 \pm 63.04$ & 90 & $148.77 \pm 123.72$ & 100 \\
\hline$p, p '-\mathrm{DDD}$ & 320 & $130.42 \pm 99.54$ & 90 & $343.39 \pm 418.96$ & 100 \\
\hline$o, p^{\prime}$-DDT & 354.5 & $14.77 \pm 16.84$ & 85 & $17.69 \pm 16.25$ & 100 \\
\hline$p, p^{\prime}-\mathrm{DDT}$ & 354.5 & $272.70 \pm 695.03$ & 90 & $481.67 \pm 96.41$ & 100 \\
\hline$\Sigma \mathrm{HCHs}$ & & $217.22 \pm 133.75$ & & $293.98 \pm 200.24$ & \\
\hline$\Sigma$ DDTs & & $522.22 \pm 753.50$ & & $1037.44 \pm 1268.32$ & \\
\hline$\Sigma O C P s$ & & $2178.89 \pm 2232.96$ & & $2916.75 \pm 2492.52$ & \\
\hline
\end{tabular}


Table 3

Compounds analyzed in different city zones $\left(\mathrm{pg} \mathrm{m}^{-3}\right)$

\begin{tabular}{|c|c|c|c|c|c|c|}
\hline & \multicolumn{2}{|l|}{ DDTs } & \multicolumn{2}{|l|}{$\mathrm{HCHs}$} & \multicolumn{2}{|l|}{$\Sigma \mathrm{OCPs}$} \\
\hline & $\mathrm{PM}_{2.5}$ & $\mathrm{PM}_{10}$ & $\mathrm{PM}_{2.5}$ & $\mathrm{PM}_{10}$ & $\mathrm{PM}_{2.5}$ & $\mathrm{PM}_{10}$ \\
\hline Industrial center & 344.97 & 1225.14 & 325.08 & 313.20 & 2356.67 & 2949.85 \\
\hline Residential & 235.77 & 748.49 & 239.13 & 338.40 & 1081.79 & 3309.12 \\
\hline Village & 691.41 & 696.30 & 126.69 & 180.07 & 1113.26 & 3528.22 \\
\hline Park & 446.93 & 457.17 & 131.99 & 373.79 & 2012.88 & 1037.63 \\
\hline Commercial & 1912.09 & 2092.75 & 249.94 & 443.01 & 3943.87 & 5293.76 \\
\hline
\end{tabular}

commercial area $>$ industrial center $>$ village $>$ park $>$ residential area while the order in $\mathrm{PM}_{10}$ was commercial area $>$ industrial center $>$ park $>$ village $>$ residential area (Table 3 ). On the one hand, the results indicated the reliability of layout for residential areas in Beijing, on the other hand, it is also suggested the management of commercial areas and industrial centers should be strengthened.

\subsection{Spatial distribution of $O C P$ s}

Spatially, southeast region of the city had the most serious OCPs pollution both for $\mathrm{PM}_{2.5}$ and $\mathrm{PM}_{10}$ (Fig. 2) while the other region had less pollution. This might relate with the fact many chemical factories laid in southeast of Beijing. Most of western

(a)

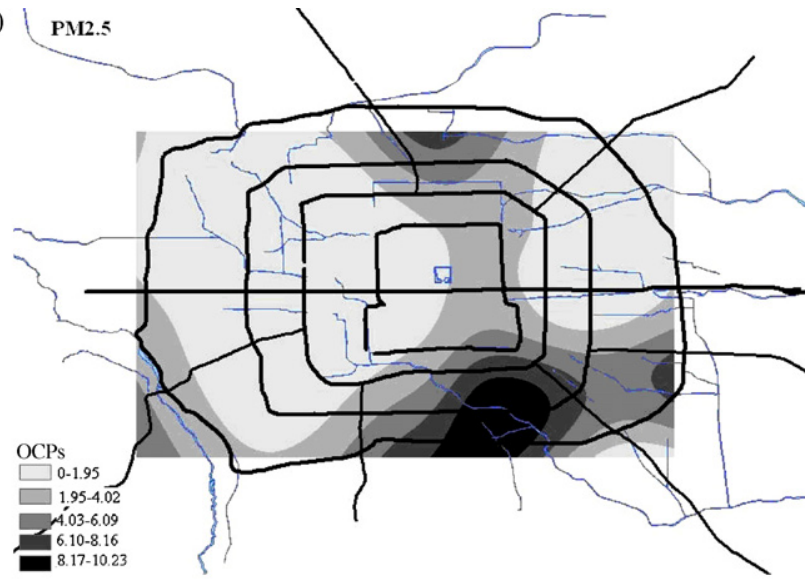

(b)

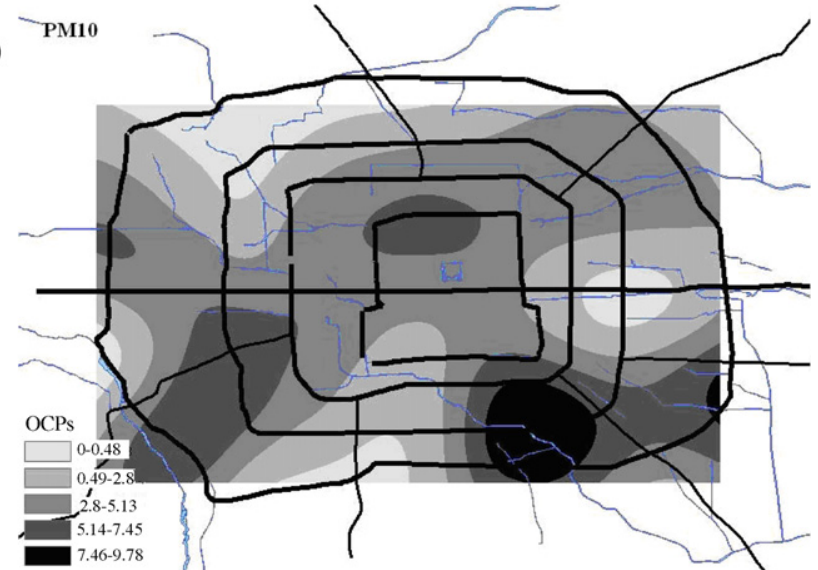

Fig. 2. Spatial distribution of OCPs in $\mathrm{PM}_{2.5}$ (a) and $\mathrm{PM}_{10}$ (b).

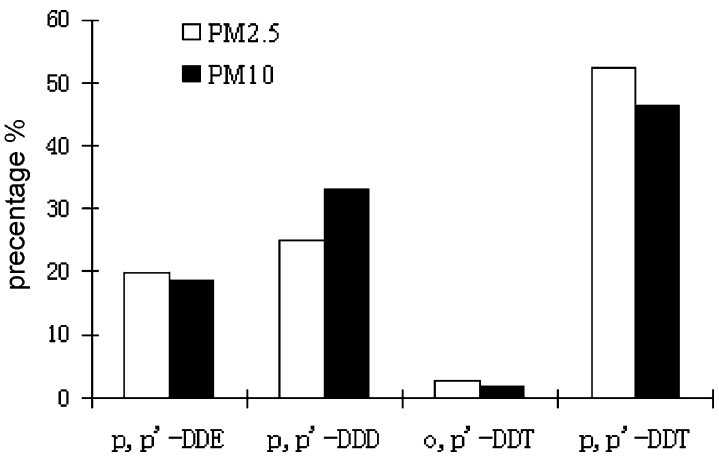

Fig. 3. percentage of DDTs in PM.

and northeast sites had least contamination of OCPs. However, $\mathrm{PM}_{10}$ received more widely pollution than $\mathrm{PM}_{2.5}$, although they were similar in tendency of OCPs distribution. This may associate with OCPs tend to absorbed by coarse particles. But for each OCP, distribution patterns are different and deserve to be discussed compound by compound.

\subsection{Component analysis}

\subsubsection{DDTs}

Technical DDT is first used to control disease-spreading insects and then as a multipurpose insecticide. Although it was banned in China in 1980s, DDT related substances can still be detected in air $[11,18]$.

$p, p^{\prime}$-DDT and its metabolites $p, p^{\prime}$-DDE and $p, p^{\prime}$-DDD are the more frequently detected DDT related compounds in this study, occurring in $90 \% \mathrm{PM}_{2.5}$ and $98 \% \mathrm{PM}_{10}$ samples (Table 2). DDTs compounds in $\mathrm{PM}_{2.5}$ and $\mathrm{PM}_{10}$ were in the range of n.d. (not detected)-2955.36 $\mathrm{pg} \mathrm{m}^{-3}$ and $7.93-3428.73 \mathrm{pg} \mathrm{m}^{-3}$ for $p, p^{\prime}$-DDT, n.d. $-415.70 \mathrm{pg} \mathrm{m}^{-3}$ and $1.56-1676.93 \mathrm{pg} \mathrm{m}^{-3}$ for $p, p^{\prime}$-DDD, n.d.-256.00 $\mathrm{pg} \mathrm{m}^{-3}$ and n.d. $-898.83 \mathrm{pg} \mathrm{m}^{-3}$ for $p, p^{\prime}$ DDE. DDTs thus shows the largest concentration range among the measured OCPs. Although the concentration of $o, p^{\prime}$-DDT (Table 2) was much less than other DDT compounds, it is relatively high compared with other research. It was reported that $o, p^{\prime}$-DDT is contained in technical dicofol as impurity, therefore, a relative high level of $o, p^{\prime}$-DDT in the environment could be result of present use of dicofol in China [19].

Technical DDT is typically composed of $77.1 \% p, p^{\prime}$-DDT, $14.9 \% o, p^{\prime}$-DDT, $4 \% p, p^{\prime}$-DDE and some other trace impurities [14]. The mean percentage of individual compounds in both $\mathrm{PM}_{2.5}$ and $\mathrm{PM}_{10}$ were as follows: $p, p^{\prime}-\mathrm{DDT}>p, p^{\prime}-\mathrm{DDD}>p, p^{\prime}-$ DDE $>o, p^{\prime}$-DDT (Fig. 3), which was different from the order of $p, p^{\prime}$-DDE $>p, p^{\prime}$-DDT $>p, p^{\prime}$-DDD $>o, p^{\prime}$-DDT reported in soils in Beijing [14]. This suggested that the DDT compounds in PM was not merely from soil release, newly input was likely existed. DDTs composition in different sampling sites showed that $p, p^{\prime}-$ DDT had a large percentage of over $50 \%$ in site 12, 13,18 and 19 for $\mathrm{PM}_{2.5}$ and site 8, 10, 11, 12 and 19 for $\mathrm{PM}_{10}$ while the percentage was less than $25 \%$ in other sampling sites, which denotes these sites could be exist new $p, p$-DDT input.

Spatially, DDT related substances in both $\mathrm{PM}_{2.5}$ and $\mathrm{PM}_{10}$ was generally highest at site 19 in the southeast, where located a 
chemical factory zone (Fig. S-1), and this might explain the high DDT levels measured there. Besides, for $\mathrm{PM}_{10}$, site $8,12,15,16$ also had high levels of $\Sigma$ DDTs. This may because of probable past usage of OCPs at these locations.

DDE and DDD have no insecticidal use and they mainly come form DDT, thus the ratio of $p, p^{\prime}-\mathrm{DDE}+p, p^{\prime}$-DDD $/ p, p^{\prime}$-DDT can be used as indicator for 'age' of DDT $[13,20] . p, p^{\prime}-\mathrm{DDE}+p, p^{\prime}-$ $\mathrm{DDD} / p, p^{\prime}$-DDT ratios in PM samples were quite variable, ranging from 0.14 to 74.45 with a median of 0.51 for $\mathrm{PM}_{2.5}$, and from 0.06 to 184.96 with a median of 0.63 for $\mathrm{PM}_{10}$. Most PM samples contained more DDE and DDD than DDT, indicating DDT residues are from 'old' sources. The lowest $p, p^{\prime}-$ $\mathrm{DDE}+p, p^{\prime}-\mathrm{DDD} / p, p^{\prime}$-DDT ratios for $\mathrm{PM}_{2.5}$ and $\mathrm{PM}_{10}$ were located in southwest and southeast sites, respectively, where high DDTs levels were found, indicating recent possible input of DDT or fresh use of dicofol since it contains about 3.5-10.8\% DDT [21]. In fact, the total input of dicofol was 50-78 ton $\mathrm{a}^{-1}$ in 1980s, 52-76 ton $\mathrm{a}^{-1}$ in $1990 \mathrm{~s}$ and $3-4$ ton $\mathrm{a}^{-1}$ in 2000 in Beijing [13]. Now, the use of Dicofol was restricted in China because relatively high levels of DDT contamination were found in environment where dicofol was applied.

\subsubsection{Chlordanes}

Technical chlordane is generally used as insecticide, herbicide and termiticide and is still being used against termites in China [13,22] with over 200 ton $^{-1}$ input recently. It is a mixture of over 140 different components, the most abundant components are trans-chlordane (TC, 13\%), cis-chlordane (CC, 11\%), heptachlor (5\%), trans-nonachlor (TN, 5\%).

TC was detected in $90 \% \mathrm{PM}_{2.5}$ and $100 \% \mathrm{PM}_{10}$ samples while $\mathrm{CC}$ was detected in $85 \% \mathrm{PM}_{2.5}$ and $90 \% \mathrm{PM}_{10}$ samples. The concentration of TC and CC were in range of n.d.-1079.9 and n.d.-216.1 $\mathrm{pg} \mathrm{m}^{-3}$ in PM2.5, respectively, 1.9-1147.7 and n.d. $-273.6 \mathrm{pg} \mathrm{m}^{-3}$ in $\mathrm{PM}_{10}$, respectively. As DDTs, a commercial site (site 19), which located near a chemical factory zone, had highest concentration of chlordanes $\left(\mathrm{TC}+\mathrm{CC}\right.$ ) for both $\mathrm{PM}_{2.5}$ and $\mathrm{PM}_{10}$. The industrial emission was the possible reason for the high levels there. A village site (site 5) and another industrial site (site 11) had the lowest concentrations for $\mathrm{PM}_{2.5}$ and $\mathrm{PM}_{10}$, respectively.

High atmospheric chlordanes levels in Beijing are likely to be associated with past pesticide use. Similarly, Harner et al. [23] and Gioia et al. [24] reported high air concentration of chlordane in urban areas, possibly resulting from past usage of chlordane in house foundations.

The TC/CC ratio is generally used for understanding the emission history and degradability of chlordane $[6,13]$. The ratio in technical chlordane mixture is $1.17[6,13,25]$. TC is generally more volatile than $\mathrm{CC}$, and if only considered volatility, the ratio at $20^{\circ} \mathrm{C}$ would be expected to be 1.41 [26]. The TC/CC ratios measured in $\mathrm{PM}_{2.5}$ and $\mathrm{PM}_{10}$ were in the range of 0-7.74 (4.15 as mean) and $0.55-8.57$ (3.63 as mean), which were much higher than that in technical chlordane. This could be attributed to the concentration difference in air. Bidleman et al. [27] reported the values of half-life in Arctic air were 8.3-9.6 years for TC and 4.1-4.8 year for $\mathrm{CC}$, whereas the half-life values were 3.2-5.2 years for TC and 5.9-9.7 years for CC in Great Lakes air [28].
The significant difference of the ratios in this study also suggested that these compounds probably originated from different pollution sources.

\subsection{3. $\mathrm{HCHs}$}

Technical $\mathrm{HCH}$ is a mixture of $60-70 \% \alpha-\mathrm{HCH}$ and $2-12 \%$ $\beta-\mathrm{HCH}$ and $10-15 \% \gamma-\mathrm{HCH}$ and other minor isomers [29]. It was banned in China in the mid-1980s. Afterwards, it was substituted by pure $\gamma-\mathrm{HCH}$ isomer (lindane). It was reported that about 3200 ton of lindane were used in China between 1991 and the usage was mainly concentrated in northern part of China [30].

During sampling period, mean concentration of $\Sigma \mathrm{HCHs}$ $(\alpha-+\beta-+\gamma-+\delta-)$ in $\mathrm{PM}_{2.5}$ and $\mathrm{PM}_{10}$ (Table 2) ranged from $4.39 \mathrm{pg} \mathrm{m}^{-3}$ to $540.39 \mathrm{pg} \mathrm{m}^{-3}$ and from $9.32 \mathrm{pg} \mathrm{m}^{-3}$ to $865.25 \mathrm{pg} \mathrm{m}^{-3}$, which comprised $8 \%$ and $9 \%$ of the total OCPs, respectively. It reflected $\mathrm{HCH}$ was one of the main OCPs pollutants in air of Beijing. The concentrations of $\beta-\mathrm{HCH}$ accounted for $18.27 \%$ and $17.09 \%$ of $\Sigma \mathrm{HCHs}$ in $\mathrm{PM}_{2.5}$ and $\mathrm{PM}_{10}$, which was lower than that in previous study (69-84\% and 56-85\% for $\mathrm{PM}_{2.5}$ and $\mathrm{PM}_{10}$ ) of PM in Beijing (2002-2003) [13]. However, the similar of the two studies was the higher concentrations occurring in fine particles and this were possibly attributed to the lower vapor pressure and higher melting point of $\beta-\mathrm{HCH}$.

Technical $\mathrm{HCH}$ mixture typically has a ratio of $\alpha-\mathrm{HCH} / \gamma$ $\mathrm{HCH}$ ranging from 4 to 7 [31]. The $\alpha-\mathrm{HCH} / \gamma-\mathrm{HCH}$ ratio in $\mathrm{PM}_{2.5}$ and $\mathrm{PM}_{10}$ ranges from 0 to 3.28 (mean 1.29) and 0 to 2.19 (mean 1.06), respectively, and were lower than that of technical $\mathrm{HCH}$. This showed that the sources of $\gamma-\mathrm{HCH}$ in aerosol of Beijing could be not only the past usage of technical $\mathrm{HCH}$, but also the use of lindane.

\subsubsection{Heptachlor (HEPT)}

HEPT is an organochlorine cyclodiene insecticide isolated from technical chlordane in 1946. It was used primarily in termite, ant and soil insect control in seed grains and on crops, as well as in the home. It is metabolized in soils to the more stable heptachlor-exo-epoxide (HEPX), which is an oxidation product formed in many plant and animal species. HEPT is moderately toxicity compound with EPA toxicity class II.

Ninety-five percent of $\mathrm{PM}_{2.5}$ sample have detectable level of HEPT and HEPX, while the two compounds present at all $\mathrm{PM}_{10}$ samples. The mean concentrations of HEPT (Table 2) were much higher than the results detected between May 2002 and April 2003 in Beijing (4.0 $\mathrm{pg} \mathrm{m}^{-3}$ and $2.2 \mathrm{pg} \mathrm{m}^{-3}$ for $\mathrm{PM}_{2.5}$ and $\mathrm{PM}_{10}$ ) [13]. Levels of HEPX were much higher than those of HEPT in both $\mathrm{PM}_{2.5}$ and $\mathrm{PM}_{10}$ (Table 2). Similar results were reported by Shen et al. [6] for air concentrations of HEPT and HEPX in North America.

As with the $\Sigma$ OCPs, highest levels of HEPX were found at site 19 for $\mathrm{PM}_{2.5}$ and $\mathrm{PM}_{10}$, a commercial site near chemical factory zone of Beijing, however, the lowest level was detected in site 5 and site 14 for $\mathrm{PM}_{2.5}$ and $\mathrm{PM}_{10}$, respectively. For HEPT, the highest concentration was detected at a building site (site 3 ) and a commercial center (site 9) for $\mathrm{PM}_{2.5}$ and $\mathrm{PM}_{10}$, respectively, while the lowest concentration was found at a village (site 5) and a residential area (site 14). 


\subsubsection{Dieldrin/aldrin}

Dieldrin and aldrin were used extensively for insect control on cotton, corn, and citrus fruit, and also used as termiticides for wooden structures [32]. In the environment, aldrin is rapidly metabolized to dieldrin. Endrin is a stereoisomer of dieldrin and was used controlling a wide range of agricultural pests, mostly on cotton. However, these compounds had never been used in large amounts in China.

In this study, aldrin was detected in more than 95\% PM samples while dieldrin was detected in $90 \%$ of PM samples. Endrin was less detectable with $85 \%$ and $90 \%$ detected in $\mathrm{PM}_{2.5}$ and $\mathrm{PM}_{10}$ samples, respectively. Concentration of aldrin in PM was about 5-7 times higher than dieldrin. The results showed high concentrations of aldrin but low levels of dieldrin, which was different from research of Gioia et al. [24] and Shen et al. [6], indicating the fresh input of aldrin in Beijing. In fact, aldrin, dieldrin and endrin were rarely used in Beijing, thus the atmospheric deposition would be the possible sources. And the air parcels from other regions outside China could also bring these compounds from aldrin frequently used countries to China.

\subsubsection{Endosulfan}

Endosulfan is a cyclodiene pesticide extensively used throughout the world to control a wide variety insects and mites. It is a highly toxic pesticide in EPA toxicity class I, and thus be restricted in many countries. However, it is still widely used in China on cotton and crops. It consists of $\alpha$ - and $\beta$-isomers. $\alpha$-Endosulfan was detectable in $95 \% \mathrm{PM}_{2.5}$ and $100 \% \mathrm{PM}_{10}$ samples, $\beta$-endosulfan in $90 \% \mathrm{PM}_{2.5}$ and $100 \% \mathrm{PM}_{10}$ samples, with the later dominating in most samples. This was opposite to what have been reported in North America by Shen et al. [6] and Gioia et al. [24]. Concentrations vary from n.d.-128.82 $\mathrm{pg} \mathrm{m}^{-3}$ and 3.86-445.44 $\mathrm{pg} \mathrm{m}^{-3}$ for $\alpha$-endosulfan in $\mathrm{PM}_{2.5}$ and $\mathrm{PM}_{10}$, respectively, n.d.-226.67 $\mathrm{pg} \mathrm{m}^{-3}$ and $3.89-569.85 \mathrm{pg} \mathrm{m}^{-3}$ for $\beta$-endosulfan in $\mathrm{PM}_{2.5}$ and $\mathrm{PM}_{10}$. A power plant (site 4) had total endosulfan concentration of $252.87 \mathrm{pg} \mathrm{m}^{-3}$ for $\mathrm{PM}_{2.5}$, which is the highest concentration found in $\mathrm{PM}_{2.5}$. An industrial center (site 10) had highest endosulfan concentration of $622.24 \mathrm{pg} \mathrm{m}^{-3}$ in $\mathrm{PM}_{10}$. These two sites are located in northeast part of Beijing, where existed agricultural land in the past, thus the high level of endosulfan is likely related to the past use in agriculture.

\subsection{7. $H C B$}

HCB was mainly used for producing pentachlorophenol sodium and as pesticide on schistosome in oncomelania. It was also used on wood preservation. Although HCB was used in many applications in the past, there are no current commercial uses of HCB as an end product in China. It is now mainly the byproduct of some technochemicals and the impurity of some pesticide. HCB is only produced in Tianjin Dagu Chemistry factory in China. By far, the total production of HCB is 79278 ton including 78323 ton used for pentachlorophenol sodium producing.

HCB detected in most of PM with concentrations varied from n.d.-113.43 $\mathrm{pg} \mathrm{m}^{-3}$ and n.d. $-263.43 \mathrm{pg} \mathrm{m}^{-3}$ in $\mathrm{PM}_{2.5}$ and $\mathrm{PM}_{10}$, respectively. The spatial distribution of $\mathrm{HCB}$ showed the
Table 4

Factor loading (varimax rotated) for organochlorine compounds

\begin{tabular}{|c|c|c|c|c|}
\hline \multirow[t]{2}{*}{ Compounds } & \multicolumn{2}{|l|}{$\mathrm{PM}_{2.5}$} & \multicolumn{2}{|l|}{$\mathrm{PM}_{10}$} \\
\hline & PC1 & PC2 & PC1 & $\mathrm{PC} 2$ \\
\hline $\mathrm{HCHs}$ & 0.246 & 0.911 & 0.211 & 0.895 \\
\hline DDTs & 0.912 & -0.053 & 0.885 & 0.023 \\
\hline $\mathrm{HCB}$ & -0.040 & 0.876 & 0.133 & 0.900 \\
\hline HEPTs & 0.916 & 0.296 & 0.908 & 0.108 \\
\hline Chlordanes & 0.224 & 0.650 & 0.814 & 0.435 \\
\hline Endosulfans & 0.933 & 0.275 & 0.144 & 0.670 \\
\hline Other OCPs & 0.967 & 0.179 & 0.879 & 0.383 \\
\hline Proportion of total variance $\%$ & 51.25 & 31.69 & 44.64 & 34.38 \\
\hline
\end{tabular}

highest levels were mainly along west and southeast part of fifth ring road for $\mathrm{PM}_{2.5}$ while those were in northeast part of the city and partly along northwest fifth ring road (Fig. S-2). The significant difference in spatial distribution is likely due to
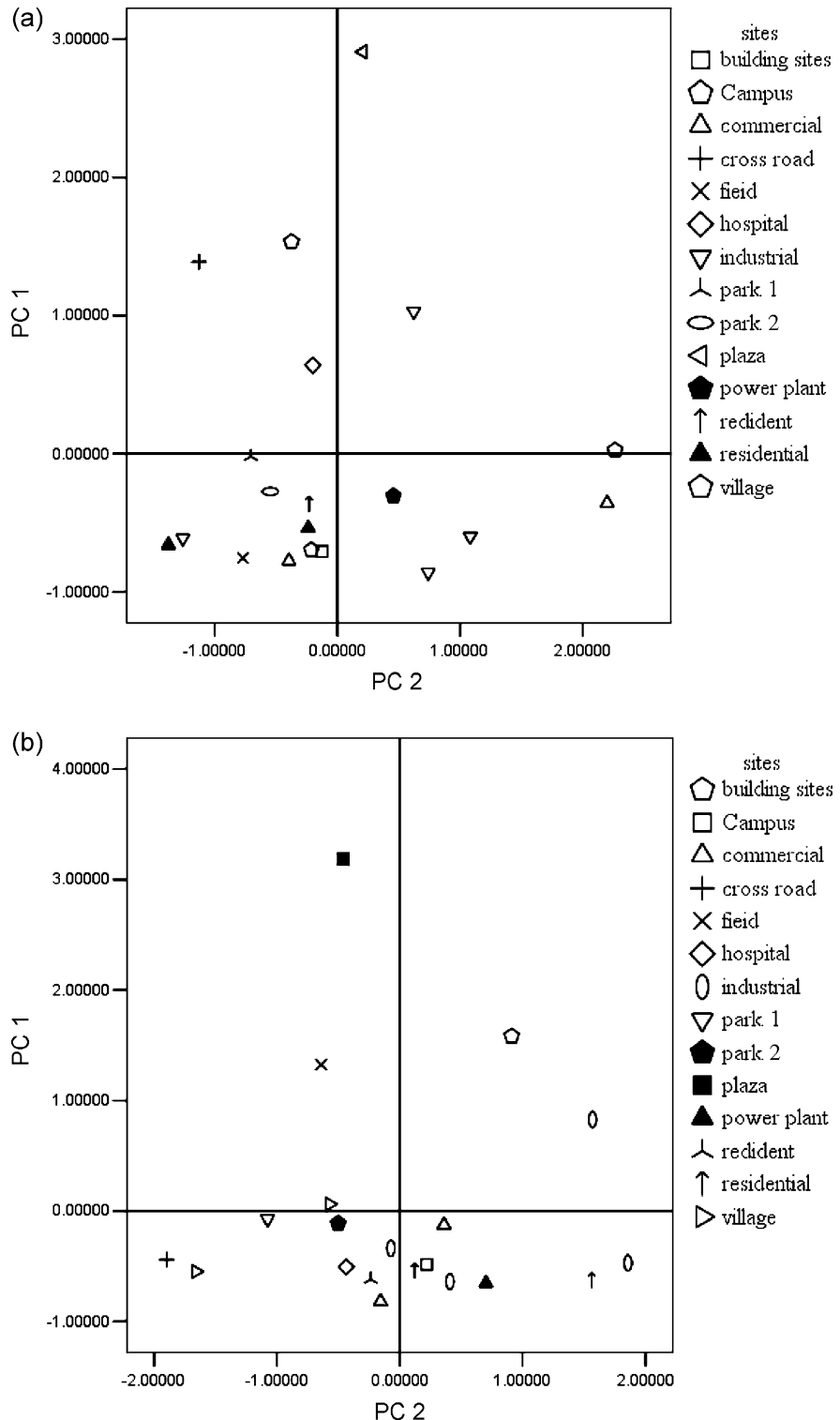

Fig. 4. Score plot of $\mathrm{PC} 1$ versus $\mathrm{PC} 2$ in $\mathrm{PM}_{10}$ (a) and $\mathrm{PM}_{2.5}$ (b). 
accumulation rate of HCB in different size particulate matters are different.

\subsection{Principal component analysis (PCA)}

In our work, PCA was conducted for 7 groups OCPs (HCHs, DDTs, HEPTs, chlordanes, endosulfans, aldrins and HCB) discussed above. As shown in Table 4, only two factors were extracted and accounted for $82.95 \%$ and $79.02 \%$ in $\mathrm{PM}_{2.5}$ and $\mathrm{PM}_{10}$, respectively. For $\mathrm{PM}_{2.5}$, the first PC (PC1) explained $51.25 \%$ of total variance, was highly associated with DDTs, HEPTs, chlordanes and aldrins, thus PC1 substantially described these four kinds OCPs contamination of the study areas. PC2 explained $31.69 \%$ of the variance in the original data. HCHs, together with $\mathrm{HCB}$ loaded significantly on PC2, indicating their same origin. Besides, endosulfans had medium loading on PC2. According to their relevance to both PC1 and PC2, we can identify PC1 and PC2 can be represented by DDTs and HCB, respectively.

The sampling sites on the PCA-score plot are shown in Fig. 4 with most of sites located near the origin. The results reflected relative low concentrations of OCPs in most $\mathrm{PM}_{2.5}$ (Fig. 4b) samples, as the origin represents the mean concentration of all samples. These sites have probably been not subjected to short range transport from local sources. Five samples (colleted from industrial area, residential center, village and crossroad) could be observed with higher loads of PC2. Three samples (from plaza, field and building sites) had pronounced loads of PC1. These sampling sites located in areas affected by industrial or agricultural activities, probably due to proximity to local emission sources.

Similar to PM2.5, PC1 (accounting for $44.61 \%$ of total variance) of $\mathrm{PM}_{10}$ significantly correlated with DDTs, HEPTs, chlordanes and other OCPs, and PC2 (accounting for $34.38 \%$ of total variance) associated with $\mathrm{HCHs}$, $\mathrm{HCB}$ and endosulfans.

The score plot of PC1 versus PC2 for $\mathrm{PM}_{10}$ (Fig. 4a) showed two industrial centers, one commercial center, one residential area and one campus had high loads on PC2, indicating the dominance of $\mathrm{HCB}$ on these sites. However, $\mathrm{PM}_{10}$ samples collected from plaza, village and crossroad had high loads on PC1, reflecting the influence of DDTs. The results also showed that the mean influence of both PC1 and PC2 on other sampling sites.

In order to examine the discrimination of samples between different land uses, subsequent PCA was performed. Considering the aforementioned outliers can mask the structure of the other data, they were eliminated before the PCA performed again. The results reflected the similar origin of $\mathrm{PM}_{2.5}$ and $\mathrm{PM}_{10}$ in most sampling sites. The score plot of PC1 versus PC2 without aforementioned sites (Fig. 5) showed samples from hospital yard, field, village, residential area and had higher loads on $\mathrm{PC} 1$ both for $\mathrm{PM}_{2.5}$ and $\mathrm{PM}_{10}$, indicating the predominance of DDTs. However, samples from park and power plant influenced much by HCB. This also reflected the land use difference on pesticide application. Altough most OCPs were banned in China, some OCPs like dicofol (o, $p^{\prime}$-DDT as impurity) is still used. We thus considered PC1 was related with both old and new input of OCPs while the PC2 was mostly from past use. In fact, field
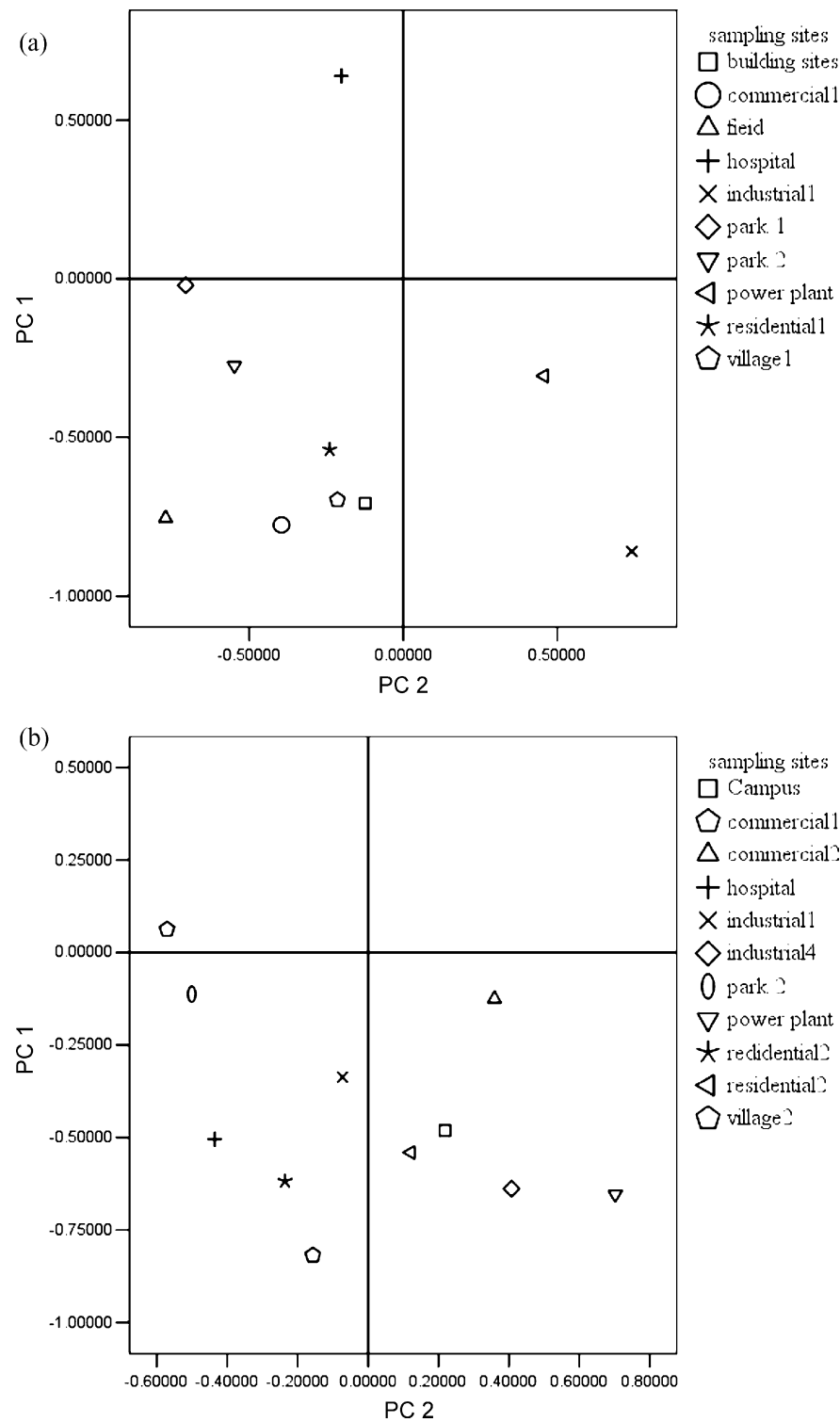

Fig. 5. Score plot of $\mathrm{PC} 1$ versus $\mathrm{PC} 2$ in $\mathrm{PM}_{10}$ (a) and $\mathrm{PM}_{2.5}$ (b) after elimination of outliers.

and village are directly associated with pesticide use, there may exist new OCPs sources. For hospital yard and residential area, chlordanes used as termiticide in house foundation can possibly explain the OCPs origin. For park and power plant, past usage of $\mathrm{HCHs}$ on park virescence and $\mathrm{HCB}$ from industrial emission could be the sources.

\section{Conclusions}

This work investigated the residue levels of OCPs in PM from Beijing, China. The results suggested OCPs levels were relatively high in comparison with other cities in China. OCPs concentrations in southeast part were higher than other part of the city, most western area and northeast sites had lest OCPs contamination.

The results of individual OCPs analysis showed most of OCPs originated from past usage, however, PM samples from some 
sites suggested newly input. PCA results displayed OCPs in both $\mathrm{PM}_{2.5}$ and $\mathrm{PM}_{10}$ samples had similar origin. PM samples from hospital yard, field, village and residential area influenced much by DDTs while those from park and power plant affected heavily by HCB.

\section{Acknowledgements}

This work was financially supported by China Geological Survey (1212010511218) and National Basic Research Program of China (2003CB415005).

\section{Appendix A. Supplementary data}

Supplementary data associated with this article can be found, in the online version, at doi:10.1016/j.jhazmat.2007.11.116.

\section{References}

[1] J.B. Dimond, R.B. Owen, Long-term residue of DDT compounds in forest soils in Maine, Environ. Pollut. 92 (1996) 1122-1130.

[2] H. Nakata, M. Kawazoe, K. Arizono, S. Abe, T. Kitano, H. Shimada, W. Li, $\mathrm{X}$. Ding, Organochlorine pesticides and polychlorinated biphenyl residues in foodstuffs and human tissues from China: status of contamination, historical trend, and human dietary exposure, Arch. Environ. Contam. Toxicol. 43 (2002) 473-480.

[3] US EPA, Endocrine Disruptor Screening and testing Advisor Committee (EDSTAC) Final Report.

[4] H. Iwata, S. Tanabe, N. Sakai, A. Nishimura, R. Tatsukawa, Geographical distributions of persistent organochlorines in air, water, and sediments from Asia and Oceans and their implications for global redistribution from low latitudes, Environ. Pollut. 85 (1994) 15-33.

[5] N. Xue, D. Zhang, X. Xu, Organochlorinated pesticide multiresidues in surface sediments from Beijing Guanting reservoir, Water Res. 40 (2006) 183-194.

[6] L. Shen, F. Wania, Y.D. Lei, C. Teixeira, D.C.G. Muir, T.F. Bidleman, Atmospheric distribution and long-rang transport behavior of organochlorine pesticides in North America, Environ. Sci. Technol. 39 (2005) 409-420.

[7] H. Hung, C.J. Halsall, P. Blanchard, H.H. Li, et al., Temporal trends of organochlorine pesticides in the Canadian Arctic atmosphere, Environ. Sci. Technol. 36 (2002) 862-868.

[8] X.P. Wang, T.D. Yao, Z.Y. Cong, X.L. Yan, S.C. Kang, Y. Zhang, Gradient distribution of persistent organic contaminants along northern slope of central-Himalayas, China, Sci. Total Environ. 372 (2006) 193-202.

[9] H. Cheng, et al., Organochlorine pesticides, polybrominated biphenyl ethers and lead isotopes during the spring time at the Waliguan Baseline Observatory, northwest, Atmos. Environ. 41 (2007) 4734-4747.

[10] K.B. Okona-Mensah, J. Battershill, A. Boobis, R. Fielder, An approach to investigating the importance of high potency polycyclic aromatic hydrocarbons (PAHs) in the induction of lung cancer by air pollution, Food Chem. Toxicol. 43 (2005) 1103-1116.

[11] S.P. Wu, J. Cao, B.G. Li, F.L. Xu, W.R. Shen, B.P. Han, R. Sun, S. Tao, Residues and distribution of organochlorine pesticides in airborne particles of different sizes from urban areas, Res. Envrion. Sci. 16 (2003) 36-39 (in Chinese).

[12] D. Xu, W. Zhong, L. Deng, Z. Chai, X. Mao, Regional distribution of organochlorinated pesticide in pine needles and its indication for socioeconomic development, Chemosphere 54 (2004) 743-752.

[13] D. Xu, M. Dan, Y. Song, Z. Chai, G. Zhuang, Concentration characteristics of extractable organohalogens in PM2.5 and PM10 in Beijing, China, Atmos. Environ. 39 (2005) 4119-4128.
[14] Y. Zhu, H. Liu, Z. Xi, H. Cheng, X. Xu, Organochlorine pesticides (DDTs and HCHs) in soils from the outskirts of Beijing, China, Chemosphere 60 (2005) 770-778.

[15] J. Li, G. Zhang, L. Guo, W. Xu, X. Li, C.S.L. Lee, A. Ding, T. Wang, Organochlorine pesticides in the atmosphere of Guangzhou and Hong Kong: regional sources and long-range atmospheric transport, Atmos. Environ. 41 (2007) 3889-3903.

[16] R. Zhou, L. Zhu, K. Yang, Y. Chn, Distribution of organochlorine pesticide in surface water and sediments from Qiantang River, East China, J. Hazard. Mater. A 137 (2006) 68-75.

[17] S.P. Wu, S. Tao, Z.H. Zhang, T. Lan, Q. Zuo, Distribution of particlephase hydrocarbons, PAHs and OCPs in Tianjin, China, Atmos. Environ. 39 (2005) 7420-7432.

[18] T. Lan, S.P. Wu, F.L. Xu, X.J. Wang, S. Tao, DDTs in airborne particles with different sizes in Tianjin during winter, J. Agro-Environ. Sci. 24 (2005) 1182-1185 (in Chinese).

[19] X. Qiu, T. Zhu, J. Li, H. Pan, Q. Li, G. Miao, J. Hong, Organochlorine pesticides in the air around the Taihu Lake, China, Environ. Sci. Technol. 38 (2004) 1368-1374.

[20] R.A. Rapaprt, S.J. Eisenreich, Atmospheric deposition of toxaphene to eastern north America derived from peat accumulation, Atmos. Environ. 20 (1986) 2367-2379

[22] C.G. Xia, Z.R. Dai, Situations of termite harmfulness and chemical control in China, Pesticide Sci Adm. (Suppl.) (2001) 16-19 (in Chinese).

[21] P. Luo, Y.M. Liu, S.Q. Fu, Analysis and evaluation of the quality of the green tea and the BHC, DDT, lead pollution in green tea in Southwest China, J. Agric. Sci. 13 (2000) 110-114 (in Chinese).

[23] T. Harner, M. Shoeib, M. Diamond, G. Stern, B. Rosenberg, Using passive air samplers to assess urban-rural trends for persistent organic pollutants. 1. Polychlorinated biphenyls and organochlorine pesticides, Environ. Sci. Technol. 38 (2004) 4474-4483.

[24] R. Gioia, J.H. Offenberg, C.L. Gigliotti, L.A. Totten, S. Du, S.J. Eisenreich, Atmospheric concentrations and deposition of organochlorine pesticides in the US Mid-Atlantic region, Atmos. Environ. 39 (2005) 2309-2322.

[25] L.M.M. Jantunen, T.F. Bidleman, T. Harner, W.J. Parkhurst, Toxaphene, chlordane, and other organochlorine pesticides in Alabama air, Environ. Sci. Technol. 34 (2000) 5097-5105.

[26] D.A. Hinckley, T.F. Bidleman, W.T. Foreman, J.R. Tuschall, Determination of vapor pressures for nonpolar and semipolar organic compounds from gas chromatographic retention data, J. Chem. Eng. Data 35 (1990) 232-237.

[27] T.F. Bidleman, L.M.M. Jantunen, P.A. Helm, E. Borströmlundén, S. Juntto, Chlordane enantiomers and temporal trends of chlordane isomers in Arctic air, Environ. Sci. Technol. 36 (2002) 539-544.

[28] D.R. Cortes, I. Basu, C.W. Sweet, K.A. Brice, R.M. Hoff, R.A. Hites, Temporal trends in gas-phase concentrations of chlorinated pesticides measured at the shores of Great Lakes, Environ. Sci. Technol. 32 (1998) 1920-1927.

[29] H. Iwata, S. Tanabe, N. Sakai, R. Tatsukawa, Distribution of persistent organochlorines in the oceanic air and surface seawater and the role of ocean on their global transport and fate, Environ. Sci. Technol. 27 (1993) 1080-1098.

[30] Y.F. Li, D.J. Cai, Z.J. Shan, Z.L. Zhu, Gridded usage inventories of technical hexachlorocyclohexane and lindane for China with $1 / 6^{\circ}$ latitude by $1 / 4^{\circ}$ longitude resolution, Arch. Environ. Contam. Toxicol. 41 (2001) 261-266.

[31] H. Karlsson, C. Derek, G. Muir, C.F. Teixiera, D.A. Burniston, W.M.J. Strachan, R.E. Hecky, J. Mwita, H.A. Bootsma, N.P. Grift, K.A. Kidd, B. Rosenberg, Persistent chlorinated pesticides in air, water and precipitation from the Lake Malawi Area, Southern Africa, Environ. Sci. Technol. 34 (2000) 4490-4495.

[32] J.L. Jorgensen, Aldrin and dieldrin: a review of research on their production, environmental deposition and fate, bioaccumulation, toxicology, and epidemiology in the United States, Environ. Health Perspect. 109 (Suppl. 1) (2001) 113-139. 